\title{
A interpretação de fenômenos religiosos contemporâneos a partir de Weber: notas inspiradas em uma leitura crítica do Novo Mapa das Religiões
}

The interpretation of contemporary religious phenomena from Weber's point of view: some notes inspired on a critical reading of The New Map of Religions

Lemuel Dourado Guerra*

\begin{abstract}
Resumo
Dentre alguns usos equivocados recorrentes das contribuições teóricas de Weber apresentadas em A ética protestante e o espírito do capitalismo, podemos citar: tratar suas interpretações como conhecimento nomotético e não ideográfico, como o pretendido pelo autor; o tratamento dos tipos ideais de capitalismo e das éticas das religiões puritanas, bem como o do catolicismo analisados no livro citado, como se fossem realidades empíricas, e não construtos conceituais abstratos; a busca da replicação contemporânea da relação, inclusive concebida como monocausal, encontrada entre a ética protestante e o surgimento e o desenvolvimento do capitalismo que surgiu na Inglaterra e Alemanha. Nesse artigo pretendemos apresentar parâmetros para a interpretação de fenômenos religiosos contemporâneos a partir das contribuições teórico-metodológicas de Weber, chamando a atenção para equívocos comuns ligados ao entendimento inadequado da proposta epistemológica weberiana apresentada e exercitada no livro citado. Fazemos isso seguindo a estrutura básica de um ensaio, no qual apresentamos uma leitura crítica da análise apresentada na pesquisa intitulada Novo Mapa das Religiões (NERI, 2011).
\end{abstract}

Palavras chave: Weber. Metodologia. Religião no Brasil. Novo Mapa das Religiões.

\begin{abstract}
This article aims to provide parameters for the interpretation of contemporary religious phenomena from the theoretical and methodological contributions of Weber, drawing attention to common misconceptions related to inadequate understanding of his theoretical and epistemological proposals presented in The protestant ethic and the spirit of capitalism. Among some of the recurring misuses of the theoretical contributions made by Weber are: a) the treatment of his interpretations as nomothetic knowledge rather than ideographic, as intended by the author; b) the treatment of ideal types of the capitalism, of the puritan religious beliefs, and of the Catholicism as if they were empirical realities and not abstract constructs; c) the search for the contemporary replication of the relationship between the Protestant ethic and the emergence and development of Capitalism in England and in Germany. In short, this essay presents a critical reading of the analysis presented in the research titled New map of religions (NERI, 2011).
\end{abstract}

Keywords: Weber. Methodology. Religion in Brazil. New Map of Religions

\footnotetext{
Artigo recebido em 30 de novembro de 2011 e aprovado em 30 de dezembro de 2011.

* Doutor em Sociologia (Universidade Federal de Pernambuco, 1999), com formação teórica na Universidade de Cambridge (UK). Atualmente é professor Adjunto III da Universidade Federal de Campina Grande, Brasil. E-mail: lenksguerra@yahoo.com.
} 


\section{Introdução}

A tese apresentada em A ética protestante e o espírito do capitalismo (WEBER, 1949) foi uma das contribuições principais elaboradas por Weber para a análise do espírito $d a$ modernidade. A partir de um estudo comparativo vasto e erudito, ele procurou entender o que seria a dinâmica central, a característica determinante que distinguiria a sociedade moderna das anteriores. Seria a racionalidade, de acordo com Weber, a utilização extensiva do modo lógico de pensar e de organizar processos e atividades, a característica principal da sociedade moderna em sua incansável busca por eficácia e eficiência e em seu desejo de controlar processos, pessoas e suas instituições.

Enquanto as sociedades anteriores se baseavam em sistemas de pensamento aparentemente irracionais, na religião, na tradição ou no carisma pessoal, a sociedade moderna tem na lógica e na aplicação da razão o fundamento do modo de pensar, de conceber as coisas e de organizar suas instituições e processos sociais. Elementos emblemáticos clássicos desse Geist des Modernität seriam a ciência, e a tecnologia, o Direito moderno e a atividade industrial e comercial. Essa é a tese mais geral que subjaz às análises da religião, da burocracia e, de modo bem particular, do capitalismo, constituindose um pressuposto da sua obra mais famosa, A ética protestante e o espírito do capitalismo (WEBER, 1949).

Não pretendemos aqui apresentar um ensaio sobre essa obra, que tem sido incansavelmente interpretada no campo das ciências sociais, justificando inclusive o comentário de que a maior parte do que se produziu desde então nesse campo não passaria de notas de rodapé da engenhosa análise oferecida por Weber na obra citada ${ }^{1}$.

Nossa preocupação neste texto é apresentar algumas sugestões de utilização adequada da análise ali oferecida, que podem ser lidas como parâmetros úteis para evitar reduções e erros comuns de manuseio das categorias e modelos propostos por Weber. Para isso, precisamos antes contextualizar alguns pontos importantes do modelo metodológicoepistemológico proposto pelo autor, para depois focalizar elementos centrais de A ética

\footnotetext{
${ }^{1}$ Conforme Roberto Motta, em aula de Teoria Sociológica, no Programa de Pós-Graduação em Sociologia da UFPE, em abril de 1988.
} 
protestante e o espírito do capitalismo, alguns erros recorrentes no uso das teses nela apresentadas, concluindo com algumas sugestões para a interpretação weberiana da pesquisa Novo Mapa das Religiões (cf. NERI, 2011).

$\mathrm{O}$ relatório denominado $\mathrm{O}$ Novo Mapa das Religiões refere-se à pesquisa coordenada por Marcelo Côrtes Neri, com a participação de L. Carvalhães e S.R.S. Monte, no âmbito do Centro de Políticas Sociais da Fundação Getúlio Vargas - CPS/FGV (Cf. NERI, 2011). O trabalho representou um esforço ambicioso e admirável de exploração de dados inéditos sobre o cenário contemporâneo das religiões no Brasil, focalizando “a evolução recente das diferentes crenças para os diversos grupos sócio-demográficos e geográficos brasileiros" (Cf. NERI, 2011, p.9). Tal pesquisa é uma versão mais recente de outro estudo, na mesma perspectiva, denominado Retratos das Religiões no Brasil, também coordenado por Marcelo Neri e produzido pelo Centro de Políticas Sociais do Instituto Brasileiro de Economia da Fundação Getulio Vargas - IBRE/FGV (Cf. NERI, 2005), que traça "um panorama da diversidade religiosa da população brasileira, analisando a evolução das diferentes crenças desde a primeira metade do século passado e algumas das principais características sócio-demográficas dos respectivos adeptos” (Cf. NERI, 2005b).

Na versão de 2011, com base no processamento e análise de microdados inexplorados com mais de 200 mil entrevistas para cada ano, sobre composição religiosa no final e no início da década passada, realizadas pelo Instituto Brasileiro de Geografia e Estatística - IBGE no âmbito da Pesquisa sobre Orçamentos Familiares - POF, são apresentadas análises de aspectos como a evolução dos números relativos à afiliação religiosa autodeclarada em termos do país, regiões e cidades, focalizando a interface entre níveis de renda, idade, gênero e preferências no que se refere à religião. São também realizadas interpretações sobre a relação entre economia e afiliação religiosa, focalizando mais especificamente as eventuais ligações entre catolicidade e o desenvolvimento econômico, tanto em nível nacional quanto internacional, as quais constituem a parte mais vulnerável do texto, originando o presente artigo. 


\section{Aspectos principais da proposta metodológico-epistemológica weberiana}

Contrapondo-se radicalmente ao modelo metodológico de Durkheim, então estabelecido como pressuposto fundamental da sociologia, Weber rejeitou como finalidade da prática de pesquisa a descoberta, ou o estabelecimento de leis ou de conclusões interpretativas válida para qualquer tempo ou lugar. Ele não acreditava na possibilidade de abranger a totalidade da vida social de modo a produzir qualquer conhecimento que pudesse ser verdadeiro universal e atemporalmente.

A ideia weberiana de produção de saber sobre o mundo social se baseia em três princípios inarredáveis:

1) a limitação da validade das interpretações às particularidades históricas estudadas;

2) o caráter múltiplo e probabilístico das relações de causalidade eventualmente construídas;

3) o caráter típico-ideal de seus conceitos, o que aponta para sua defesa do construcionismo social, em termos epistemológicos.

Desta forma, a abrangência da interpretação apresentada em A ética protestante e o espírito do capitalismo se referiria às especificidades históricas a partir das quais Weber construiu seus tipos ideais mais citados: o de ética protestante (rigorosamente falando, da ética calvinista), o de capitalismo e, eu diria mais, o de catolicismo.

Assim, qualquer tentativa de replicação mecânica da análise weberiana, pensando em termos de mimetização da análise oferecida das afinidades eletivas entre a ética calvinista e o espírito do capitalismo nascente, corre o risco de trair a proposta metodológico-epistemológica de Weber e de abrir espaço para análises equivocadas, como veremos na seção final, em relação ao artigo que inspirou essas breves notas. 


\section{As linhas gerais de A Ética Protestante e o Espírito do Capitalismo}

Weber conclui, em seu livro, a partir de uma comparação massiva de dados referentes a sociedades e religiões do passado e do presente dele, que algumas idéias religiosas estimulavam a mudança social e outras a dificultavam. O principal argumento de A ética protestante e o espírito do capitalismo não é o de que a religião é o fator causal determinante do desenvolvimento econômico (como frequentemente é dito). Pensando especificamente o capitalismo nascente e as amplas e radicais mudanças sociais que ele implicava, Weber concluiu que as éticas protestantes, mais particularmente as das seitas puritanas (calvinistas, luteranas e wesleyanas) ofereciam modelos de comportamento que guardavam estreita e forte afinidade com as necessidades do modus operandi da revolução industrial/capitalismo, em termos de concepção do mundo e organização do cotidiano dos indivíduos.

As linhas gerais da comparação entre as seitas puritanas e suas éticas com o catolicismo e outras grandes religiões daquele período histórico podem ser assim sintetizadas:

1) Enquanto o catolicismo de então ensinava que a pobreza era o caminho para a salvação e que o céu estava na vida além-morte, o puritanismo declarava que a riqueza individual era um sinal da predestinação divina para a salvação. Trabalhando duro e tornando-se rico, os calvinistas buscavam convencer a si mesmos e aos outros de que tinham sido escolhidos para a salvação, sendo o sucesso nos negócios a marca indelével de que não iriam para o inferno. Entretanto, e isso era fundamental para o capitalismo nascente, a riqueza adquirida através do trabalho árduo não deveria ser desperdiçada em prazeres e luxos terrenos, mas sim poupada para mais investimento e consequente incremento da prova da bênção divina sobre o sujeito. Em contraste com os católicos ricos, que esbanjavam de modo extravagante as riquezas herdadas, os puritanos eram conhecidos pela sua frugalidade, simplicidade e pela rejeição de todas as formas mundanas de

prazer. Esse desejo de poupar ao invés de gastar teria favorecido o espírito de investimento tão vital ao capitalismo nascente. 
2) Enquanto grandes religiões como o catolicismo e o islamismo subordinavam os indivíduos ao coletivo, ao ritmo e desejos expressos em termos da massa de fiéis e da estrutura hierárquica verticalizada, os puritanos eram mais individualistas e democráticos. Em contraste com a autoridade do papa, bispos e padres, os puritanos eram encorajados a procurar sua salvação e a falar diretamente com Deus. Esse traço de individualismo representou, também, para Weber uma afinidade eletiva entre as éticas puritanas e o capitalismo nascente.

3) Enquanto outras religiões se fundamentavam em rituais, crenças e mesmo na magia, o protestantismo era mais racional, rejeitando rituais extravagantes e todas as formas irracionais de explicação, o que representou também um elemento de contato significativo com a racionalização dos processos produtivos e de todas as esferas da vida social permeadas pela lógica capitalista de produção.

4) Enquanto as outras religiões partilhavam de um imaginário que definia o trabalho enquanto algo a ser realizado apenas para manter os padrões existentes de vida, e o lucro era visto como algo suspeito, para os puritanos o trabalho duro e a acumulação de renda eram o caminho para a certificação da salvação, da escolha e favorecimento divinos.

As afinidades eletivas entre dois tipos ideais, a ética calvinista e o espírito do capitalismo moderno, apontam menos para uma explicação monocausal, no estilo positivista, e mais para a defesa da importância concomitante das ideias e das relações de produção na moldagem dos cotidianos dos indivíduos, de suas disposições para a ação, as quais cumulativamente vão moldando os macroambientes, a história.

O valor da contribuição weberiana apresentada em A ética protestante e o espírito do capitalismo se refere a sua proposta de restaurar o peso das ideias na explicação das mudanças sociais de todas as ordens, inclusive a econômica, além de enfatizar a importância da agência individual numa época de hipertrofia da abordagem estruturaleconomicista, que frequentemente desconsiderava os fatores culturais e o enfoque nos atores sociais. 


\section{Erros comuns da utilização da metodologia e da interpretação weberiana}

1) Encarar os tipos ideais enquanto categorias reais, históricas

O expediente do tipo ideal prevê a elaboração conceitual - a partir dos interesses e do enfoque definido pelo cientista interessado na explicação de um determinado fenômeno - de um conjunto de características, de elementos determinantes e constitutivos de uma abstração que toma como base aspectos da realidade, sem nunca pretender a descrição objetiva da mesma. Desse modo, é equivocada a interpretação objetivista das análises específicas das afinidades eletivas entre as éticas protestantes (puritanas) e o espírito do capitalismo moderno (alemão, inglês), bem como a procura nas realidades contemporâneas a reprodução das relações conceituais elicitadas pela análise weberiana apresentada em A

\section{ética protestante e o espírito do capitalismo.}

O tipo ideal, segundo Weber,

é uma tentativa de analisar configurações históricas particulares. Ele é um constructo conceitual que não pretende reproduzir uma realidade histórica ou mesmo uma realidade "verdadeira". Ele não é nem mesmo um esquema sob o qual a realidade pode ser subsumida como uma "instância". Ele tem o significado de um conceito limitante que deve servir como parâmetro de comparação em relação a realidades históricas específicas, para produzir eventuais explicações de aspectos/elementos considerados importantes, a partir dos interesses do pesquisador. (WEBER, 1949, p. 93)

2) Usar as interpretações de individualidades históricas feitas por Weber como leis gerais durkheimianas (com contingência lógica; universais; verdadeiras sempre; naturalmente necessárias - não acidentais)

A formulação típico-ideal das éticas protestantes (dos puritanos) e do capitalismo moderno nascente corresponde ao momento histórico específico em que Weber escreve. A própria comparação das religiões denominadas de protestantes com o catolicismo somente deve ser tomada em referência às particularidades das individualidades históricas focalizadas. 
Weber não acreditava numa análise causal válida para todas as sociedades e temporalidades. Para ele, as regularidades eventualmente observadas deveriam ser algo a ser explicado pela análise da individualidade histórica focalizada, em termos típico-ideais e não funcionariam como pontos de chegadas, como outputs da prática científica, mas como pontos de partidas para a análise dos fenômenos eventualmente relacionados.

É recorrente o equívoco tanto em termos teóricos quanto analíticos daqueles que pretendem usar a tese apresentada em A ética protestante e o espírito do capitalismo como uma lei geral para compreender o desenvolvimento econômico, a dinâmica do capitalismo ou quaisquer outros fenômenos do campo religioso ou econômico. Weber não estabeleceu nenhuma lei geral. As afinidades eletivas observadas entre as éticas puritanas e o capitalismo se referem às particularidades históricas consideradas, devendo estas serem entendidas no contexto da formulação conceitual resultante dos interesses de pesquisa de Weber.

\section{3) Confundir afinidades eletivas com monocausalidade}

Outra confusão recorrente na literatura que comenta a tese apresentada por Weber em A ética protestante e o espírito do capitalismo é o entendimento equivocado das afinidades eletivas entre as éticas das religiões protestantes puritanas e o espírito do capitalismo na Alemanha e na Inglaterra como uma relação causal - considerando a(s) ética(s) protestante(s) a causa determinante do desenvolvimento econômico capitalista. Aqui são cometidos dois erros: transformar a relação de associação entre os dois termos numa relação causal; e pensar o capitalismo como o resultado de uma púnica causa, o que significa atribuir a Weber uma explicação monocausal do fenômeno, algo que ele rejeitou veementemente em termos metodológico-espistemológicos. Para Weber a causalidade no mundo da cultura tem sempre um caráter probabilístico e seria sempre plural. 


\section{Sugestões de pontos para a interpretação weberiana do novo Mapa das Religiões no Brasil}

Para finalizar nosso artigo, apresentamos a seguir algumas sugestões de elementos e maneiras de focalizar a relação entre campo religioso e sociedade/economia em geral e especificamente em relação à utilização das reflexões apresentadas por Weber em A ética protestante e o espírito do capitalismo na pesquisa que originou as reflexões aqui trazidas.

1) O catolicismo mudou, como também se transformaram o capitalismo e o contexto sóciohistórico em que ambos existem

Falar das relações entre catolicismo e economia/capitalismo tomando como referência a análise weberiana apresentada em A ética protestante e o espírito do capitalismo é um equívoco, já que tanto o catolicismo brasileiro é diferente daquele discutido por Weber, quanto a configuração do sistema capitalista, do cenário social e econômico são diferenciados.

As conclusões apresentadas por Weber segundo as quais o catolicismo se inclinaria a obstacularizar o desenvolvimento do capitalismo nascente somente podem ser compreendidas se consideradas no contexto histórico por ele focalizado.

Elementos tais como a condenação do lucro, a associação com o desperdício de recursos nos prazeres da carne associados com o catolicismo europeu discutido por Weber podem não estar mais presentes nos regimes de vida do(s) catolicismo(s) contemporâneo(s), o que aponta para a necessidade de colocar em outros termos a associação negativa encontrada por Weber entre o imaginário e a ética católicos e o desempenho econômico dos indivíduos em geral.

A hegemonização do valor dos bens materiais, do sucesso econômico, da associação entre ganhar dinheiro e ser feliz, por exemplo, a importância do planejamento racional, do investimento no crescimento pessoal são elementos que perpassam todos os setores da vida social contemporânea em muitas sociedades ocidentais, inclusive suplantando eventuais contravalores eventualmente associados a setores do campo religioso. 
2) O paradigma da semelhança e a análise da diversidade das mensagens religiosas e de seus efeitos no cotidiano dos indivíduos

Outro elemento importante a ser considerado na análise dos dados do Novo Mapa das Religiões (NERI, 2011) no Brasil é o processo de assemelhação entre muitas das principais mensagens religiosas em competição no campo religioso. Segundo Berger (1986), ao competir pela preferência dos mesmos segmentos de fiéis, as mensagens religiosas tenderiam a se assemelhar. São muitos os sinais dessa mimetização entre religiões no Brasil. Dentre elas podemos citar o campo da música, os temas das mensagens, o vestuário, as estratégias de proselitismo, as atividades oferecidas (cf. GUERRA, 2001; 2003).

No período em que Weber escreveu A ética protestante e o espírito do capitalismo, as diferenças eram marcantes, o que justificava uma diferenciação clara entre os Regulamentos de Vida associados a católicos e a luteranos, calvinistas ou wesleyanos. Atualmente um indivíduo se diz católico, mas canta músicas dos evangélicos, freqüenta acampamentos/retiros espirituais parecidos com os anteriormente oferecidos somente pelos batistas ou pentecostais, pode ter o carisma da glossolalia e quem sabe é um seguidor fervoroso da Teologia da Prosperidade, anteriormente somente encontrada nos cultos e mensagens do Bispo Macedo.

Dada essa assemelhação, é difícil construir associações e relações de causalidade referidas aos efeitos dos modelos de religiosidade associados a instituições e mensagens religiosas nos cotidianos dos indivíduos, bem como em termos macroeconômicos, sem cair no erro da redundância pela duplicidade de entradas em termos de éticas religiosas.

3) Os índices de crescimento econômico associados com as altas taxas de autodeclarados católicos se baseiam em séries históricas - proporcionalidade do crescimento em relação a níveis de desenvolvimento historicamente observados

A relação apresentada entre desenvolvimento econômico e mudanças nos números relativos ao campo religioso, apresentadas no Novo Mapa das Religiões, é também questionável, na medida em que as estatísticas relativas ao crescimento econômico se 
baseiam numa abordagem cronológica linear, enquanto as associações apresentadas entre religiosidade (ser ou não ser católico) e desempenho econômico de cidades e regiões não apresentam a mesma estratégia analítica, sendo mais do tipo vertical do que longitudinal.

Assim, as mudanças econômicas refletidas, por exemplo, no crescimento econômico maior da região Nordeste do que da região Sudeste, por exemplo, deveriam ser compreendidas em termos de análise econômica pontual, levando em consideração, os efeitos, por exemplo, das políticas assistencialistas inauguradas nos dois mandatos de Lula, cuja repercussão tende a aparecer de modo superestimado em termos estatísticos absolutos, do que se considerados em termos proporcionais.

Por outro lado, seria preciso também considerar as especificidades atualmente verificadas em referência ao ser católico, diluídas nas estatísticas. Sob essa rubrica temos reunidos os que apenas se declaram católicos, denominados na literatura pertinente como católicos tradicionais; os que se encontram ligados a grupos carismáticos, denominados de católicos pentecostais, os quais se filiam a projetos éticos bem semelhantes aos dos pentecostais evangélicos; os católicos radicais, como os que participam das novas comunidades de Vida e Aliança, os quais seguem éticas radicais, inclusive com elementos de contestação do consumismo. Essa diversidade dentro do catolicismo também precisaria ser considerada, caso os pesquisadores tenham a intenção de estabelecer nexos explicativos entre os índices estatísticos de catolicismo e os de crescimento econômico.

\section{Trechos específicos do Novo Mapa das Religiões comentados}

No Novo Mapa das Religiões, que inspirou essas notas reflexivas, há uma tendência a estabelecer de modo automático a relação entre taxas referentes ao catolicismo e os índices econômicos, sem o cuidado necessário de demonstrar os elementos que poderiam explicar a conexão causal sugerida. Confunde-se uma associação estatística geral ente dois índices de campos diferenciados (o religioso e o econômico) com o proposto por Weber, que estabeleceu a relação de influência entre os dados estatísticos do campo empresarial-econômico e os referentes à afiliação religiosa através da demonstração das afinidades eletivas entre os preceitos éticos dos calvinistas e a cultura do capitalismo nascente - e as práticas dela decorrentes. Ao esquecer esse detalhe fundamental a qualquer 
estabelecimento de relações causais de qualquer tipo e mais especificamente daquele tipo sugerido por Weber - de caráter probabilístico e plural - ou mesmo de associação entre variáveis ou fenômenos, o Novo Mapa das Religiões apresenta uma série de análises e de conclusões apressadas tanto sobre a economia secular quanto sobre a economia da religião. Vejamos alguns exemplos:

1) “Qual a porcentagem de renda apropriada por cada grupo religioso?” (NERI, 2011, p. 9)

Esse tipo de pergunta aponta para uma associação automática entre afiliação religiosa e níveis de renda. Concordamos que pode haver uma associação entre as duas variáveis, mas para que essa ligação seja avaliada, concluída, tematizada, pesquisas que ultrapassem os dados estatísticos precisariam ser realizadas, a exemplo do realizado por Weber em A ética protestante e o espírito do capitalismo.

O Brasil não é só o país com a maior população católica do mundo, como simbolicamente é o único que integra o grupo dos maiores países emergentes dos BRICs. $\left[{ }^{2}\right]$ O dado comum aos países submergentes do chamado grupo dos PIIGS (Portugal, Irlanda, Itália, Grécia e Espanha/Spain) é o catolicismo. Como reflexo do estado da economia, em Madrid, ocorreram na última semana uma série de protestos contra os custos da jornada. Se Max Weber fosse vivo, veria na crise econômica atual uma confirmação de sua tese sobre A ética protestante e o espírito do capitalismo publicada 106 anos atrás. (NERI, 2011, p. 11)

Mais uma vez a associação entre performance econômica nacional e taxas da economia religiosa são apresentadas em relação causal. Desse modo a expressão economia católica parece apontar para a religiosidade como determinante do mercado em todas as suas variáveis, resultando em desempenhos melhores ou piores das economias nacionais com base na hegemonia de um ou de outro modelo de religiosidade. Além das observações já apresentadas acima, que apontam para o equívoco de reduzir a explicação do desempenho econômico à variável religião, apontamos a fragilidade revelada inclusive no próprio parágrafo citado, já que a citada confirmação da tese weberiana na associação entre catolicismo e decadência econômica (nos países do PIIGS) teria que enfrentar o desafio de

\footnotetext{
${ }^{2}$ Os países emergentes compõem o grupo denominado BRIC: Brasil, Rússia, Índia, China [Nota do Editor].
} 
explicar a ascensão da economia (católica) brasileira e, no mesmo caminho, a da economia chinesa, dentre outros exemplos.

A parte final do parágrafo também é um sacrilégio em relação à teoria/epistemologia weberiana, já que ignora os aspectos acima comentados do estilo weberiano de explicação do social, segundo o qual o conhecimento do mundo humano/da cultura não pretende ser nomológico, geral, mas referido às individualidades históricas focalizadas, a partir de tipos ideais concebidos a partir das decisões do pesquisador.

3) “Seria o Brasil dos idos do século XXI uma exceção à tese weberiana?” (NERI, 2011, p.11)

Essa formulação se adequa a conclusões de pesquisa do estilo nomotético, que se constroem enquanto leis gerais, capazes de explicar a relação entre fenômenos em todos os lugares e temporalidades. Na lógica weberiana essa é uma falsa questão, já que as relações entre catolicismo e capitalismo ou performance econômica se referiria à particularidade histórica analisada, como já exposto acima. de inadequação do capitalismo ao crescimento capitalista são a regra. Entre as 27 unidades da Federação, os mais católicos são os nordestinos, com 74\% de sua população. Estes estados estão crescendo mais do que os demais. De 2001 a 2009 a renda do NE cresceu 41,8\%, contra 15,8 do Sudeste, a região menos católica, com 64,3\% de sua população. (NERI, 2011, p. 12)

Nessa análise repete-se o equívoco já indicado referente ao uso de uma interpretação weberiana referida a uma particularidade histórica como uma lei a ser verificada e se demonstra a completa desconsideração das dinâmicas sócio-econômico-políticas atualmente em curso no Brasil, em cujo âmbito as mudanças indicadas acontecem, reduzindo a interpretação dos índices de crescimento observados nas regiões católicas do Brasil à força da variável religiosa, sem que o modus operandi da causação seja minimamente explicado. 


\section{Conclusão}

A pesquisa aqui comentada é interessante no que se refere aos novos dados sobre a economia da religião e deve ser utilizado como material precioso para a realização de novos projetos de pesquisa que se destinem a produzir o que parece ser a principal lacuna da discussão nele apresentada - a explicação dos achados estatísticos apontados, tais como os recentes índices de queda do catolicismo e da ascensão de evangélicos, bem como das religiões alternativas e dos sem religião.

Valeria a pena, por exemplo, pensar a continuidade de uma série de fatores já apontados na literatura para explicar o descenso dos católicos e o crescimento dos evangélicos, tais como:

1) $O$ peso da organização da Igreja Católica, o qual se desdobra, por exemplo, na insuficiência de pessoal (padres) para atender à demanda dos fiéis pelos serviços religiosos, causada tanto pela crise vocacional, quanto pela longa duração da formação de sacerdotes, enquanto os pontos de oferecimento da mensagem religiosa dos evangélicos se multiplicam geometricamente e rapidamente (cf. GUERRA, 2003).

2) A limitação da Igreja Católica em adequar as mensagens e ênfases religiosas às demandas dos consumidores de religião, tanto no que se refere ao conteúdo quanto à forma (embalagens, estratégias de marketing). Para dar suporte a essa interpretação, basta comparar as incursões televisivas e dos meios de comunicação em geral de denominações evangélicas e as da Igreja Católica.

3) A expansão do catolicismo carismático pode ter determinado também a diminuição da própria autodeclaração de afiliação religiosa tradicionalmente utilizada sob a expressão católico não praticante, que pode ter se transformado na crescente autodeclaração de sem religião, num momento em que a própria mensagem católica carismática insiste na necessidade conversão dos católicos a um certo catolicismo genuíno. 
Concluímos estas reflexões reafirmando a riqueza dos dados trazidos pelo Novo Mapa das Religiões aqui comentado, no que se refere ao comportamento dos índices de católicos e de protestantes, por exemplo, mas também no que se refere ao campo do gênero e da geração, cuja interpretação exigirá dos pesquisadores um esforço intelectual efetivo, para o qual pretendemos também contribuir.

\section{REFERÊNCIAS}

BERGER, Peter. O Dossel Sagrado: elementos para uma teoria sociológica da religião. São Paulo: Paulinas, 1986.

CROWELL, Ethan. Weber's 'Protestant Ethic' and his Critics. 2006. Dissertação (Mestrado) - Texas University at Arlignton.

GUERRA, Lemuel Dourado. Mercado Religioso no Brasil - competição, demanda e a dinâmica da esfera da religião. João Pessoa: Idéia, 2003.

GUERRA, Lemuel Dourado. O Paradigma da Semelhança. Revista Ariús. Campina Grande, n. 9, p. 27-37, 2001.

LEHMANN, H; ROTH, G. Weber's Protestant Ethic: Origins, Evidence, Context. Berlin: German Historical Institute, 1993.

LÖWY, Michael. Catholic Ethics and that the Spirit of Capitalism - The Unwritten Chapter in Max Weber's Sociology of Religion. Instituto de Estudos Avançados. São Paulo, 2006. Disponível em <http://www.iea.usp.br/english/articles/>. Acesso em 01 nov. 2011

MACRAE, D. Weber. London: Fontana, 1974.

NERI, Marcelo Côrtes (Coord.). Novo Mapa das Religiões. Rio de Janeiro: FGV-CPS, 2011. Disponível em: <http://cps.fgv.br/ren>. Acesso em 01 nov. 2011.

NERI, Marcelo. Retratos da Religião no Brasil. Centro de Políticas Sociais, Fundação Getulio Vargas, 2005. Disponível em <http://www.fgv.br/cps/religioes/inicio.htm>. Acesso em 01 nov. 2011.

NERI, Marcelo. Retratos da Religião no Brasil. Centro de Políticas Sociais, Fundação Getulio Vargas, 2005b. Disponível em <http://www.fgv.br/cps/religioes/Apresenta\%C3\%A7\%C3\%A3o/Religi\%C3\%B5es_Guiad eBancodadosGeral.pdf>. Acesso em 01 nov. 2011.

PARKIN, F. Max Weber. London: Tavistock, 1982. 
PAMPEL, F. C. Sociological Lives and Ideas: an Introduction to the Classical Theorists. Basingstoke: Macmillan, 2000.

SLATTERS, Martin. Key Ideas in Sociology. Cheltenham, UK: Nelson Thornes, 2003.

TURNER, B.S. Max Weber: From History to Modernity. London: Routledge, 1992.

WEBER.Max. A ética protestante e o espírito do capitalismo. São Paulo: Companhia das Letras, 2004.

WEBER, M. The protestant ethic and the spirit of capitalism. London: Allen \&Unwin, 1949. 